
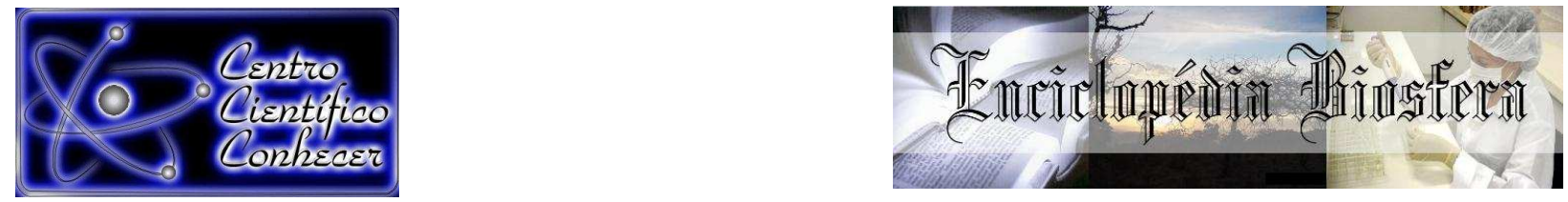

\title{
MORFOLOGIA DO PÂNCREAS DE Tamandua tetradactyla (TAMANDUÁ MIRIM) (LINNAEUS,1758)
}

Geise Helen Romoda Sardinha ${ }^{2}$; Adriano Luiz Pimenta ${ }^{2}$; Isane Vera Karsburg ${ }^{1}$; Mendelson Lima ${ }^{1}$; Gerlane de Medeiros Costa ${ }^{1}$.

${ }^{1}$ Faculdade de Ciências Biológicas e Agrárias - Universidade do Estado do Mato Grosso - UNEMAT - Rodovia MT 208, Km 147 s/n, Jardim Tropical - Alta FlorestaMT- Brasil CEP: 78.580-000 Caixa Postal 324 -

2 Acadêmicos do Curso de Licenciatura e Bacharelado em Ciências Biológicas da Universidade do Estado do Mato Grosso. Campus de Alta Floresta - MT, Brasil., Campus I, Rodovia MT 208 Km 147, Alta Floresta, MT 78.580-000, Brasil. Email: geisesardinha@hotmail.com

Recebido em: 08/09/2015 - Aprovado em: 14/11/2015 - Publicado em: 01/12/2015 DOI: http://dx.doi.org/10.18677/Enciclopedia_Biosfera_2015_022

\begin{abstract}
RESUMO
O Tamandua tetradactyla (tamamduá-mirim) é um animal de porte médio, hábitos solitário, crepuscular e arborícola, que se alimenta de formigas, cupins, abelhas e mel. O objetivo deste estudo foi e caracterizar a arquitetura macro e microscópica do pâncreas de $T$. tetradactyla, gerando informações básicas para conhecimento de sua biologia. Foi utilizado um exemplar da coleção Zoológica da Universidade do Estado do Mato Grosso - UNEMAT, Campus Alta Floresta, sobre número de tombamento nํ 0364. O pâncreas se mostrou como um órgão denso, com superfície levemente ondulada, cortado medianamente pelo ducto pancreático, apresentando regiões de cabeça, corpo e calda bem definidos. Histologicamente, toda superfície externa do órgão se mostrou revestida por uma bimembrana de epitélio pavimentoso, seguido de tecido conjuntivo frouxo com fibroblastos, constituindo por lobos, separados por septos interlobulares. O órgão se mostrou similar ao de outras espécies de vertebrados.
\end{abstract}

PALAVRAS- CHAVE: Digestório, glândula, Morfologia, Xenarta.

\section{MORPHOLOGY OF PÂNCREAS IN Tamandua tetradactyla (COLLARED ANTEATERS) (LINNAEUS,1758).}

\begin{abstract}
The Tamandua tetradactyla (Collared anteaters) is a medium-sized animal, solitary habits, twilight and arboreal, feeding on ants, termites, bees and honey. The aim of this study was to describe the macro and microscopic architecture of the pancreas of the $T$. tetradactyla generating basic information for knowledge of their biology. Was used a copy of the Zoological Collection of the University of Mato Grosso State UNEMAT, Campus Alta Floresta, number of Tombo no 0364. The pancreas was shown as a dense body, with slightly wavy surface, cut medially by the pancreatic duct, with regions of head, body and well-defined syrup. Histologically, the entire outer surface of the body proved to be coated with a bimembrana of squamous ENCICLOPÉDIA BIOSFERA, Centro Científico Conhecer - Goiânia, v.11 n.22; p.3056 2015
\end{abstract}


epithelium, followed by loose connective tissue with fibroblasts, constituting by wolves, separated by interlobular septa. The body showed similar ace of other vertebrate species.

KEYWORDS: Gland, Digestory, Morphology, Xenarta.

\section{INTRODUÇÃO}

O tamanduá-mirim (Tamandua tetradactyla) ocorre na América do Sul a leste dos Andes, da Venezuela até o norte da Argentina, Uruguai e Brasil, onde pode ser encontrado em todos os biomas (Amazônia, Caatinga, Cerrado, Mata Atlântica, Pantanal e Pampa). A espécie p porte médio, cauda semi-preênsil com presença de alguns pelos curtos e duros, corpo coberto por pelos curtos, densos e grossos, de coloração amarelada na porção ventral e escura no dorso, formando um desenho semelhante a um colete preto. $T$. tetradactyla possue olfato bastante desenvolvido, língua longa, produzem saliva altamente colante que auxiliam na captura do alimento, e por possuírem dentes rudimentares, o alimento é triturado no estômago (TAVARES \& KOENEMANN, 2008; CHINEM, 2010).

O tamanduá-mirim pertence à ordem Xenarthra, apresentando comportamento e metabolismo letárgicos, o que se relaciona de forma direta ao seu hábito alimentar, constituído de alimentos pouco energéticos, tais como formigas, cupins, abelhas e mel. Para conseguir o alimento, ele utiliza suas fortes garras para fazer buracos no cupinzeiro e a língua para capturar os insetos (TAVARES \& KOENEMANN, 2008).

Para auxiliar no processo de digestão química dos alimentos, o $T$. tetradactyla apresenta anexa ao tubo digestório, o pâncreas, considerada uma glândula mista, com funções endócrinas e exócrinas, secretando hormônios e enzimas digestivas. $O$ componente endócrino são as ilhotas pancreáticas (ilhotas de Langerhans), as quais representam cerca de $2 \%$ do volume total do pâncreas (KIERSZENBAUM \& TRES, 2012), enquanto que o pâncreas exócrino constitui a maior parte da glândula, formada por estruturas tubuloacinosas ramificadas. A porção exócrina secreta água, íons e diversas proteinases que são enzimas digestivas (JUNQUEIRA \& CARNEIRO, 2008). O órgão em animais domésticos está localizado na porção dorsal da cavidade abdominal, limitando-se com a porção ventral do estômago e alças duodenais, dorsal ao baço e ao pólo cranial do rim esquerdo (GETTY, 1986). Segundo DAMIAN et al., (2010) a topografia não apresenta grandes diferenças entre as espécies.

Em Rhea americana (Ema), ave Rheiforme da família Rheidae, o pâncreas foi descrito como um órgão longo em formato de fita fina, achatado e de coloração amarelo claro, formado por um lobo dorsal e um lobo ventral (RODRIGUES et al., 2012). Segundo KIERSZENBAUM \& TRES (2012) o pâncreas, usualmente de formato triangular, está organizado em quatro componentes anatômicos: cabeça, na altura da segunda e terceira alças duodenais; colo, em contato com as veias mesentéricas superiores; corpo, posicionado obliquamente no mesentério; e cauda, terminando próximo ao hilo do baço. Histologicamente esta glândula apresenta-se constituída por lóbulos separados por septos de tecido conjuntivo, onde estão dispersos vasos sanguíneos, linfáticos, nervos e ductos excretores (JUNQUEIRA \& CARNEIRO, 2008; KIERSZENBAUM \& TRES, 2012).

Pouco se conhece sobre a anatomia desta espécie, embora tenham sido realizados trabalhos referentes à sua morfologia como o de MACHADO \& SANTOS 
(2008) que descreveram a topografia do cone medular, de FERREIRA et al. (2011) que observaram o suprimento sanguíneo do intestino delgado. ROSSI et al. (2011) observaram os órgãos genitais femininos, MELUL et al. (2010) descreveram a anatomia do sistema reprodutor masculino, PINHEIRO et al. (2012) relataram os ramos colaterais do arco aórtico, PINHEIRO et al. (2014) os aspectos morfológicos do estômago e REZENDE et al., (2013) a biologia reprodutiva da espécie. Desta forma, o objetivo deste estudo foi caracterizar a arquitetura macro e microscópica do pâncreas de $T$. tetradactyla, gerando informações básicas para conhecimento de sua morfo-anatomia.

\section{MATERIAL E MÉTODOS}

Para a realização deste trabalho, foi utilizado um macho jovem de Tamandua tetradactyla (tamanduá-mirim), coletado em óbito pelo Resgate de Fauna da Companhia Hidrelétrica Teles Pires e depositado em 02/2011 na coleção Zoológica da Universidade do Estado do Mato Grosso - UNEMAT, Campus Alta Floresta, sobre número de tombamento oㅡ M 0015, fixado em formaldeído a $10 \%$. O exemplar foi dissecado em 07/2014, tendo sido utilizado instrumental básico para dissecação. Foi realizada incisão ventral longitudinal, ao longo da linha alba, abrindo-se uma janela para exposição dos órgãos. O órgão foi fotografado in situ e posteriormente foram retirados fragmentos e colocados em álcool $70 \%$ overnight, seguido de desidratação em concentrações crescentes de etanol (75\% a 100\%), diafanizados em xilol, incluídos em parafina Histosec-MERCK, de onde foram retirados cortes histológicos com $5 \mu \mathrm{m}$ de espessura, corados pelas técnicas de Hematoxilina-Eosina (HE) (TOLOSA et al., 2003). A fotodocumentação microscópica foi realizada com auxílio de fotomicroscópio Leica ICC50 HD.

\section{RESULTADOS E DISCUSSÃO}

O pâncreas de $T$. tetradactyla estava localizado na porção dorsal da cavidade abdominal, lateralmente ao duodeno, estendendo-se sobre o mesentério entre a primeira e segunda alças intestinais, ventral ao estômago e dorsolateral ao baço (Fig. 01A). Apresentou-se como um órgão denso, de coloração rósea, superfície levemente ondular e formato levemente foliar. Pode-se observar que o órgão era constituído pelas regiões de cabeça, corpo e calda bem definidos. A cabeça localizava-se lateralmente à primeira alça intestinal e se mostrou como a porção mais ampla do órgão (Fig. 01B). As regiões de corpo e cauda estendiam-se lateralmente ao comprimento do duodeno, dorsal ao jejuno, entre a segunda e terceira alças intestinais. Estas regiões se estendiam lateralmente em um formato digitiforme, tendo sido observado dividindo, superficialmente, o órgão, um ducto pancreático. Este ducto dividia o pâncreas em superfície dorsal e superfície ventral (Fig. 01C). 


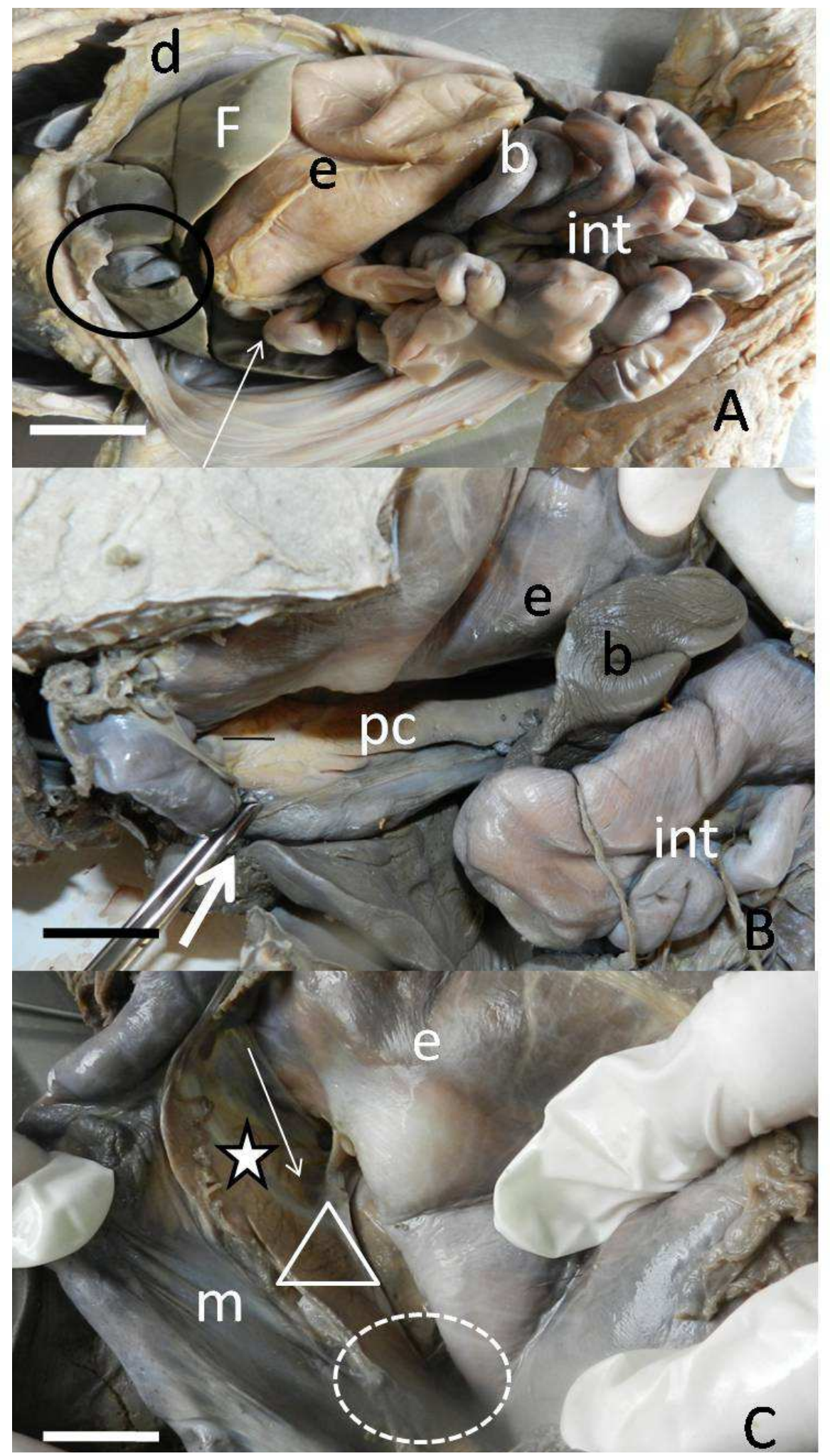

FIGURA 1- Localização anatômica do pâncreas de T. tetradactyla. A) Visão ventral, distribuição crânio-caudal dos órgãos na cavidade abdominal - músculo diafragma (d), fígado (F), vesícula biliar (círculo), estômago (e), duodeno (seta fina), baço (b) e intestino delgado (int). Barra $1 \mathrm{~cm}$. B) Visão dorsal do pâncreas (pc), lateral ao duodeno (seta), ventral ao estômago (e), dorsolateral ao baço (b), dorsal ao intestino delgado (int). Barra $1 \mathrm{~cm}$. C) Vista da região dorsal do pâncreas inserido ao mesentério $(\mathrm{m})$, observando-se a porção de cabeça (estrela), corpo (triangulo) e cauda (círculo pontilhado) e cortando medianamente o órgão, o ducto pancreático $(\mathrm{dp})$. Barra $1 \mathrm{~cm}$. 
Anatomicamente, foi descrito para suínos um pâncreas de formato triangular, fixado à primeira curvatura do duodeno, e em ruminantes, quase que totalmente localizado à direita do plano mediano do corpo, constituindo-se por um grande lobo direito e um menor esquerdo, unidos ao lado direito da veia porta, constituindo a região de corpo do órgão (GETTY, 1986). Em ratos brancos Wistar, topograficamente este órgão estava localizado retrodiafragmático, na flexão do duodeno, na região craniana sublombar, em contato com a parede dorsal da cavidade abdominal, próximo a arteria aorta, veia cava caudal, tronco da artéria celíaca e rim direito, apresentando as regiões de cabeça, corpo e cauda ( DAMIAN et al, 2010). RIZZO et al. (2014), descreveram o pâncreas de Euphractus sexcinctus (tatu-peba) como um órgão de coloração amarelo opaca. Em Rhea americana (emas), o órgão se apresentou longo, achatado e de coloração amarelo claro, apresentando-se, ventralmente, como uma fita fina, formado por dois lobos, um lobo dorsal e um lobo ventral (RODRIGUES et al., 2012). As características topograficas e anatomicas o pâncreas de $T$. Tetradactyla se mostraram similares às descritas para outras espécies na literatura.

A superfície externa do órgão era revestida por uma bimembrana de epitélio pavimentoso e tecido conjuntivo frouxo com fibroblastos (Fig.02A). S constituído por lobos, separados por septos interlobulares formados por tecido conjuntivo frouxo não modelado. Dispersos no tecido conjuntivo foram observados vasos sanguíneos, ductos e fibras musculares (Fig. 02B); e uma camada de tecido adiposo (Fig. 02C).

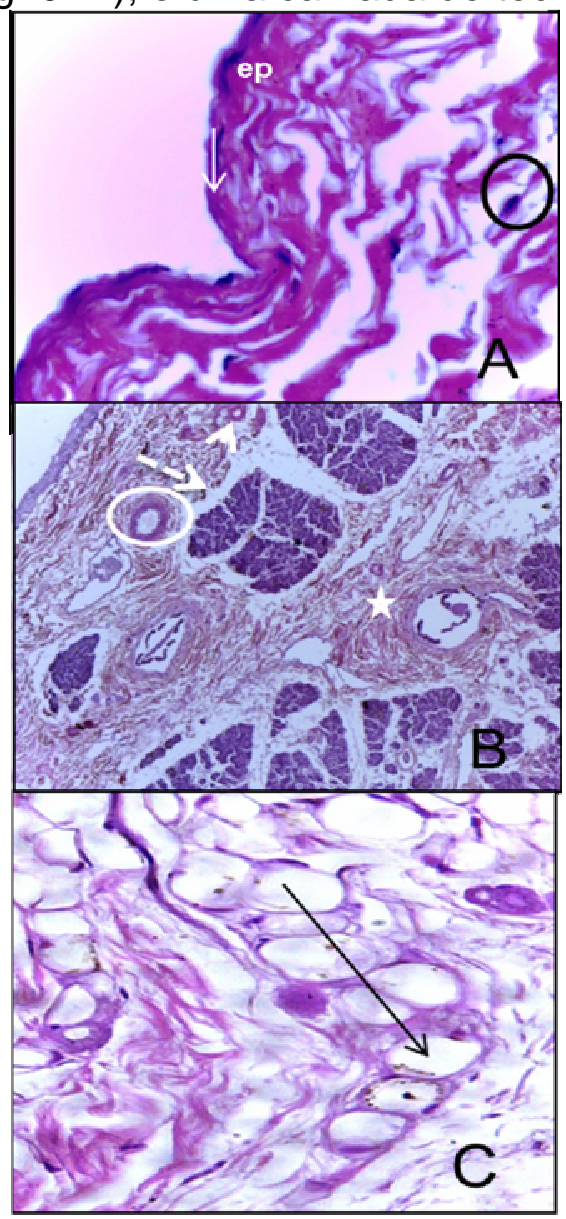

FIGURA 2. Fotomicrográfica do pâncreas do T. tetradactyla. A) Túnica de revestimento constituída por uma bicamada de epitélio pavimentoso (seta). Epitélio pavimentoso (ep), fibroblasto (círculo preto). Aumento: 40x. B) tecido conjuntivo frouxo (estrela), fibras musculares (seta pontilhada branca), vasos sanguíneos (cabeça da seta branca), ducto pancreático (circulo branco). Aumento: 10x. C) Tecido adiposo (seta preta). Aumento: 10x. 
A partir da camada de tecido conjuntivo, formavam-se os septos que se invaginavam separando o parênquima e formando os lóbulos pancreáticos (Fig. 03A). O parênquima é constituído por ácinos serosos, formados por células centroacinosas de formato cubóide, com um núcleo basal e um pequeno ducto central. Estes ácinos separados por pequenos septos interacinares os quais puderam ser observados capilares sinusóides sanguíneos (Fig. 03B). As ilhotas de Langlerhans se mostraram como um agloramento de células dispersa no parênquima (Fig. 03C). Os ductos pancreáticos observados dispersos nos septos interlobulares apresentaram paredes espessas constituídas por epitélio colunar estratificado circundando um lúmen (Fig. 03D).

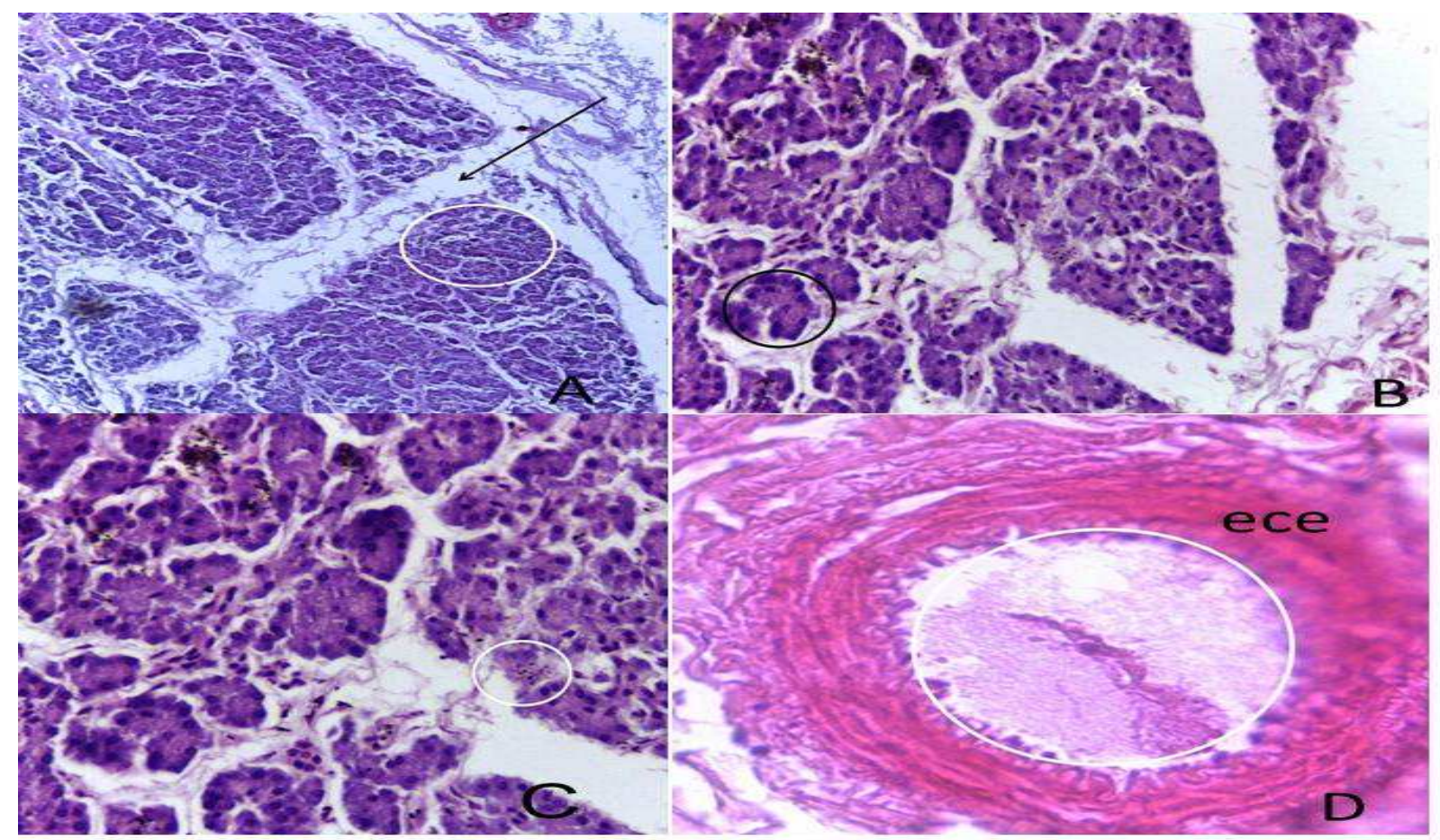

FIGURA 3. Fotomicrográfica do pâncreas do $T$. tetradactyla. A) Evidenciando um lóbulo pancreático (círculo branco), tecido conjuntivo se invaginando e formando septo (seta preta). Aumento: 10x. B) Ácino seroso com um pequeno ducto central (círculo preto), pequenos septo que dividem os lóbulos em ácinos (estrela). Aumento: 40x. C) ilhotas de Langherans (círculo branco). Aumento: 40x. D) mostrando ducto pancreático com a parede espessa constituída por epitélio colunar estratificado (ece), lúmen de aparência (círculo branco). Aumento: 100x.

Microscopicamente foi descrito que o pâncreas de emas ( $R$. americana) era composto por uma cápsula delgada de tecido conjuntivo frouxo, a qual emitia septos que dividiam o órgão em lóbulos, compostos por estruturas túbulo alveolares e ductos (RODRIGUES et al., 2012). Em Galus galus (galinhas campestres), KADHIM et al. (2010) descreveram uma fina camada de tecido conjuntivo revestindo o órgão, da qual se estendiam septos que o separavam em lóbulos. Nesse tecido conjuntivo, foram observados vasos sanguíneos, linfáticos e ductos excretores. No parênquima foram encontradas poucas ilhotas de Langerhans e estas eram irregulares. Resultados semelhantes foram descritos por HODGES (1974) em galinhas domésticas. Em Euphractus sexcinctus (tatu peba) o órgão era recoberto por uma ENCICLOPÉDIA BIOSFERA, Centro Científico Conhecer - Goiânia, v.11 n.22; p.3061 2015 
delgada e densa cápsula de tecido fibroso, unida ao parênquima por tecido conjuntivo frouxo, a porção exócrina era composta por numerosas formações excretoras acinares, já a as ilhotas de pancreáticas encontravam-se disseminadas entre lobos de maior tamanho (RIZZO et al., 2014).

\section{CONCLUSÃO}

O pâncreas de Tamandua tetradactyla é similar com o mesmo orgão de espécies domésticas, modelo experimental (rato Wistar) e espécies silvestres como ema, tatu-peba e galinhas campestres, diferindo apenas na lobação. Microscopicamente, apresentou características semelhantes as histológicas descritas para vertebrados, de parênquima e estroma, com porção exócrina constituindo a maior parte do órgão e escassa concentração de ilhotas pancreáticas.

\section{REFERÊNCIAS}

CHINEM, S. Tamanduá-mirim. Fundação Parque Zoológico de São Paulo. 2010 Disponível em:http://www.zoologico.sp.gov.br/mamíferos/tamanduá. Acessado em: 23 ago. 2014.

DAMIAN, A; MICLAUS, V; PAPUC,I. Morphological Studies of the Pancreas in the White Wistar Rat. Veterinary Medicine, v. 67, n. 1, p.45-48. 2010.

FERREIRA, J. R.; SOUZA, A. L. R.; MORTOZA, A. R.; REZENDE, L. C. Vascularization of the small intestine in lesser anteaters, Tamandua tetradactyla (Xenarthra: Myrmecophagidae). Zoologia, Curitiba, v. 28, n. 4, p. 488-494, 2011.

GETTY, R. Anatomia dos animais domésticos. 5.ed. Rio de Janeiro: Guanabara Koogan, 2v, pp.1001, 1986.

HODGES, R.D. The histology of the fowl. London: Academic, p.35-88.1974.

JUNQUEIRA, L. C.; CARNEIRO, J. Histologia básica. 11 ed. Rio de Janeiro: Guanabara Koogan, pp 524, 2008.

KADHIM, K. K. ; ZUKI, A. B. Z.; NOORDIN, M. M.; BABJEE, S. M. A.; ZAMRI-SAAD, M. Morphological study of pancreatic duct in red jungle fowl. African Journal of

Biotechnology, v. 9, n. 42, p. 7209-7215, 2010.

KIERSZENBAUM, A.; TRES, L. L. Histologia e Biologia Celular. 3 ed. Rio de Janeiro, Elsevier Editora Ltda, pp.699, 2012.

MACHADO, G. V.; SANTOS, B. S. Topografia do cone medular no tamanduá-mirim (Tamandua tetradactyla Linnaeus, 1758) (Xenarthra: Myrmecophagidae). Archives of Veterinary Science, Curitiba, v. 13, n. 3, p.172-175, 2008.

MELUL, R.; BRANCO, E.; SOUZA, A. C. B.; PEREIRA, L. C. ; LIMA, A. R. Descrição morfológica do sistema reprodutor masculino de tamanduá-mirim (Tamandua tetradactyla LINNAEUS, 1758) estudos preliminares. Anais do 8 Seminário Anual de Iniciação Científica e 2º Seminário de Pesquisa da UFRA. 2010. 
PINHEIRO, V. L. C.; LIMA, A. R.; PEREIRA, L. C.; GOMES, B. D.; BRANCO, E. Descrição anatômica dos ramos colaterais do arco aórtico do tamanduá-mirim (Tamandua tetradactyla). Biotemas, Santa Catarina, v. 25, n. 2, p. 133-137, 2012.

PINHEIRO, A.C. O; LIMA, A.R; CARVALHO, A.F; PEREIRA, L.C; BRANCO, É. Aspectos morfológicos macro e microscópicos do estômago de tamanduá-mirim (Tamandua tetradactyla). Arquivos Brasileiros Medicina Veterinária Zootecnia, v. 66, n. 4, p.1089-1096, 2014.

REZENDE, L.C; GALDOS-RIVEROS, A.C; MIGLINO M.A; FERREIRA J.R. Aspectos da biologia reprodutiva em preguiça e tamanduá: uma revisão. Revista Brasileira Reprodução Animal, Belo Horizonte, v. 37, n. 4, p. 354-359, 2013.

RIZZO, M. S.; SANTOS, G. A.; FORTES, E. A. M.; PINHEIRO, B. C.; SILVA, A. B. S.; CAVALCANTE, M. M. A. S.; CONDE JUNIOR, A. M. Morfologia do pâncreas de tatu-peba (Euphractus sexcinctus) (Linnaeus, 1758). Revista Interdisciplinar Ciências e Saúde - RICS. International Symposim of Morphogenesis and Cell Differentiation. Piaui. 2014

RODRIGUES, M. N.; OLIVIERA, G. B. DE; SILVA, R. S. B. DA; ALBUQUERQUE, J. F. G. DE; MIGLINO, M. A., OLIVEIRA, M. F. Morfologia e topografia do fígado e pâncreas de emas Rhea americana. Ciência Rural, Santa Maria, v. 42, n. 3, p. 474479, 2012.

ROSSI, L.F.; LUACES, J. P.; MARCOS, H. J. A.; CETICA, P. D.; GACHEN, G.; JIMENO, G. P.; MERANI, M. S. Female reproductive tract of the lesser anteater (Tamandua tetradactyla, Myrmecophagidae, Xenarthra). Anatomy and Histology. Journal of Morphology, v. 272, p. 1307-1313, 2011.

TAVARES, S. V.; KOENEMANN, J. G. Ocorrência de Tamandua tetradactyla (Linnaeus, 1758) (Xenarthra, Myrmecophagidae) no município de Itaqui, fronteira oeste do Rio Grande do Sul, Brasil. Revista Biodiversidade Pampeana, Goiania, v. 6, p. 30-33, 2008.

TOlOSA, E. M. C.; RODRIGUES, C. J.; BEHMER, O. A.; FREITAS-NETO, A. G. Manual de Técnicas para Histologia Normal e Patológica. 2 ed. São Paulo, Manole, pp.331, 2003. 